This is a pre-published version of a chapter in a book available from Edward Elgar:

https://www.e-elgar.com/shop/gbp/research-handbook-of-global-leadership-9781782545347.html

Suggested citation: Mäkelä, K., Lauring, J., Butler, C. L., Lee, H.-J., Lücke, G., Miska, C., Pahlberg, C., \& Stahl, G. K. (2020). Meeting the challenges of globalization in order to make a difference: implications for teams and team leadership. In L. Zander (ed.), Research Handbook of Global Leadership: Making a Difference. Edward Elgar, pp.91-107.

\title{
Meeting the challenges of globalization in order to make a difference: Implications for teams and team leadership
}

\author{
Kristiina Mäkelä \\ Aalto University School of Business, Finland \\ Jakob Lauring \\ Aarhus University, Demark \\ Christina Butler \\ Kingston Business School, Kingston University, UK \\ Hyun-Jung Lee \\ Department of Management, London School of Economics, UK \\ Gundula Lücke \\ Department of Business Studies, Uppsala University, Sweden \\ Christof Miska \\ WU Vienna, Austria \\ Cecilia Pahlberg \\ Department of Business Studies. Uppsala University, Sweden \\ Günter K. Stahl \\ WU Vienna, Austria
}




\begin{abstract}
In this chapter we suggest that globalization of businesses brings with it three new challenges that teams need to face. These include an increase in the number of internal and external stakeholders to manage; the need to interact across more and different types of boundaries; and an increasing necessity to integrate local responsiveness and global coordination. We focus on how these new globalization challenges impact teams in general and team leadership in particular, and how team leaders can make a difference by developing specific capabilities to address them.
\end{abstract}

\title{
Introduction
}

Although people have connected across distance for a long time, recent globalization trends mean that today's organizations operate in a very different environment than they have done in the past. The world is increasingly 'flat' (Friedman, 2005), in that organizations and individuals from anywhere in the world compete in a more even playing field than ever before. The advantages of global connectedness are many: Multinational organizations have wider opportunities to bring relevant but separate bodies of knowledge together (Kogut \& Zander, 1993), integrate internal and external influences on a global scale (Doz, Sanots \& Williamson, 2001), and increase creativity and innovativeness (Hargadon \& Sutton, 1997; Østergaard, Timmermans, \& Kristinsson, 2011) both at the organizational and the societal levels (Polonsky \& Jevons, 2009).

The widespread use of global teams, referred to as geographically distributed and culturally diverse work groups that have a joint goal (Kearney, Gebert, \& Voelpel, 2009; Zander, Mockaitis \& Butler, 2012), is one key means through which organizations have sought to leverage these advantages (Klitmøller \& Lauring, 2013). Global teamwork allows organizations to integrate specialized and geographically dispersed units and processes without being tied to a specific location, which is why such teams have become an increasingly popular means of horizontal coordination (Hambrick, Davison, Snell, \& Snow, 1998). Global teams are superior means of knowledge integration in that they allow different perspectives and bodies of knowledge to come together at the level of the hands-on daily work of the organization (Mäkelä \& Brewster, 2009), and they have been associated with both higher creativity and innovation than homogenous co-located teams (Stahl, Maznevski, Voigt \& Jonsen, 2010; Stahl, Mäkelä, Zander \& Maznevski, 2010; ZellmerBruhn \& Gibson, 2006).

Teams also face significant challenges driven by the very same forces of globalization. Environmental complexity has increased tenfold, as organizations have to navigate and negotiate across a variety of different geographical, cultural, linguistic and social contexts and boundaries (Carlile, 2004; Westney, 2001). New types of communication and work routines have to be developed (Morrison, 2000), and team leaders need to rethink basic notions on what it takes to manage a team (Zander, Zettinig \& Mäkelä, 2013). Not surprisingly an increasing number of scholars pursue a better understanding of how globalization challenges can and will impact teamwork. Extant literature on global teams has tended to focus on internal team dynamics, such as cultural diversity and dispersion, and their effects on various team processes and outcomes (Stahl et al., 2010; Zander \& Butler, 2010). We add to this that globalization also brings other important complications that go beyond these; in particular, we see (1) an increase in the number of internal and external stakeholders that the team has to manage, (2) the related need to interact across more and different 
types of boundaries, and (3) an increasing necessity to integrate local responsiveness with global coordination on the team level (Palazzo, 2002). In this chapter, we focus on how these new globalization challenges impact teams in general, team leadership in particular, and how team leaders can make a difference by developing specific capabilities to address them.

The chapter is structured as follows: We first discuss how global teams are affected by new challenges of more stakeholders, multiple boundaries and the need to balance local responsiveness with global integration, brought about by the globalization of business (Yagi \& Kleinberg, 2011). Second, we then suggest that three particular roles and capabilities - boundary spanner, bridge maker and blender - can enable team leaders (and members) to overcome these challenges. Third, we illustrate both the challenges and the team leader capabilities through an in-depth case of a team leader facing a decision whether or not to increase the proportion of women at higher management levels at the Japanese operation of a major German bank. Lastly, we conclude with a discussion on the theoretical and practical implications of our assessment of how global leaders can make a difference in a team embedded in a globalized world.

\section{Globalization challenges and teams}

To say that globalization is upon us and here to stay is self-evident. Conducting global, international and cross-cultural business has become a normal part of everyday life in most contemporary large organizations. For many companies the key effect of globalization is that of increased worldwide competition and business complexity; and even medium- and small-sized companies, which themselves may be less active in international markets, experience globalization through their interactions with customers, competitors, suppliers or employees among others (Alon \& Higgins, 2005).

One organizational response to such challenges has been the establishment of global teams. Multinational teams of all shapes and sizes are often seen to be at the 'heart' of globalization (Snow, Snell, Canney Davison, \& Hambrick, 1996) and an attractive way of organizing a specialized workforce. However, although global teamwork is highly useful for many international business endeavors, such teams do not always deliver as expected (Distefano \& Maznevski, 2000; Stahl et al., 2010). For example, Govindarajan and Gupta (2001) found that only 18 percent of the 70 multinational teams they studied were successful and as much as one-third were considered unsuccessful - a fairly typical distribution of organizational outcomes of such teams (Zander and Butler, 2010). In this regard Mendenhall, Reiche, Bird and Osland (2012) suggest that the challenges global team leaders have to face are characterized by multiplicity, interdependence, ambiguity and flux. Osland, Bird and Oddou (2012) even argue that the leadership of global team should be seen as extreme leadership due to those challenges.

Potential pitfalls are many. For one, global teams vary in terms of their degree of cultural, linguistic and functional diversity (Maloney \& Zellmer-Bruhn, 2006), which influences team cohesion negatively (Stahl et al., 2010). In addition, virtual or semi-virtual teamwork builds on collaboration between individuals dispersed between different time zones and countries, which makes interaction more challenging than in diverse but co-located teams (Gibbs, 2009; Järvenpää \& Leidner, 1999). In sum, global teams face far greater complexity than traditional teams in terms of the tasks they deal with, the diversity of people who are involved, and the time and technology related issues they have to solve. 
In addition to these issues that are largely related to team-internal processes, globalization also brings about new types of broader challenges, including a growth in the number of internal and external stakeholders, the associated need to cross multiple different boundaries, and the increasing requirement for balancing local responsiveness with global integration; these will be discussed next.

\section{The stakeholder diversity challenge}

An organizational stakeholder can be defined as an individual or a group, which is or can be affected by the decisions and actions of the organization or has potential for influencing policies, products and services concerning that organization (Freeman, 1984). Such organizational stakeholders could include employees, boards of directors, suppliers, creditors, investors, owners, customers, unions, policy makers or local communities, and they may hold different and even contrasting interests. Organizations can best create value when they are able to join the interests of many stakeholders, for example by simultaneously addressing the needs and preferences of customers, employees and stockholders (Fassin, 2012).

In order to address the globalization challenge of stakeholder diversity from a team perspective, we distinguish between team-internal stakeholders and team-external stakeholders. Team-internal stakeholders are simply the members (and the leader) of the team. Team-external stakeholders can be company-internal (but team-external) actors such as the home units of the various team members, top management or other relevant teams; company-external market stakeholders are outside parties who engage in economic transactions with the team or non-market stakeholders who affect or are affected by the team's actions (such as the general public, local communities, activist groups, business support groups or the media) (Freeman, 1984).

Considering team members and outside groups as stakeholders moves our focus beyond issues of team diversity to the importance of competing objectives, interests and priorities. The above groups all potentially affect the way the team works, and the team has to both connect with and balance the interests of these stakeholders. Some of these stakeholder groups will be visible and vocal, others more silent, but the team needs to be mindful of their various influences and integrate this broader set of interests in order to make a sustained difference.

\section{The multiple boundaries challenge}

As a direct result of having to deal with an increasing number of stakeholders, teams also face new challenges of interaction. Global teamwork involves crossing of many barriers on daily basis. While extant team literature has recognized many of these challenges, it has tended to focus on team-internal interaction processes (see e.g., Stahl et al., 2010 for a summary). The new challenge brought by globalization is the existence of a multitude of different simultaneous boundaries (both in terms of number and variety) and the necessity to deal with them not only in team-internal but also in team-external interactions. As external interactions are characterized by less frequency, less rich communication channels and delayed feedback as compared to teaminternal interactions, communication issues become amplified and more difficult to overcome (Distefano \& Maznevski, 2000; Maznevski \& Chudoba, 2000).

We identify several different boundaries associated with linguistic, cultural and different intra- and inter-organizational differences. First, increasing globalization creates more linguistic boundaries, and since language affects almost all aspects of everyday life this can have important 
consequences (Chomsky, 1992). Linguistic boundaries within or across teams are caused by the presence of a multitude of speakers of different national languages and imply a lack of mutual intelligibility, or understandability, between two or more languages (Chiswich \& Miller, 2005; Lauring \& Selmer, 2010). There can also be boundaries caused when sharing a common language (e.g., a corporate language), if it is spoken in different ways or with different levels of proficiency, including pronunciation, grammatical structures and conventions and knowledge about using the language where applicable (Clément \& Gardner, 2001) or different vocabulary, phrases, spellings and accents (Klitmøller \& Lauring, 2013).

Second, cultural boundaries are also crossed by global teams. The term cultural boundary refers to dissimilarities in basic aspects of national culture, such as core values, beliefs, customs and rituals as well as legal, political and economic systems (Brannen \& Salk, 2000; Hambrick et al., 1998; Jackson et al., 1995). Cultural diversity has long been acknowledged to create significant challenges to internal cohesion, communication effectiveness and knowledge sharing within teams (Gibson, 2001; Stahl et al., 2010), but it also crucially influences interaction across team boundaries. For example, differing deep-level attitudes towards hierarchy or differences in orientation towards the group versus individuals can make cross-boundary interaction difficult (Ash, 2008; Epton et al., 1985; Jackson et al., 1995; Jehn et al., 1999; McLeod \& Lobe, 1992). What is more, there are significant cultural differences in communication styles, that is, variations in socio-linguistic knowledge and ways of expressing oneself (Henderson, 2005), and these may become a significant obstacle to interaction and power relationships, such as different speech communities misperceiving other communities as lacking charisma, intelligence, confidence or leadership abilities (Gudykunst, 2004; Li, 1999; SanAntonio, 1987).

Third, internal or external organizational boundaries are crossed to a much larger extent. Organizational boundaries are often described as imaginary dividers meant to distinguish an organizational unit from external but nearby influences and from other units (Boland \& Tenkasi, 1995; Carlile, 2004). They represent boundaries for specific practice patterns and thus moving across them may mean that competencies and behaviors are evaluated differently in different contexts (Fiol, 1989). Given the globalization-imposed reorganizations of the value chain, organizational boundaries (including both intra- and inter-organizational ones) have become increasingly fuzzy and permeable, leading to both ambiguity and communication challenges (Yagi \& Kleinberg, 2011).

\section{The local responsiveness versus global integration challenge}

The third related challenge that global teams increasingly face is that of finding a balance between local needs and the needs of global integration. Bartlett and Ghoshal (1989) have argued that multinational corporations always face the competing forces of global integration and local responsiveness: On the one hand, most international firms want to achieve a degree of consistency across their global operation, saving duplication costs and taking maximum advantage of wellproven successful practices across national boundaries (Birkinshaw \& Hood, 1998; Brock \& Siscovick, 2007; Luo, 2001). On the other hand, globally integrated corporate practices may not always suit the management needs or specific circumstances of local units that arise from differences in market conditions and political environments (Hannon, 1995; Yu, Subramaniam \& Cannella, 2009). To an increasing degree successful global organizations must be able to do both: differentiate in order to operate successfully in local markets, and integrate in order to effectively drive corporate performance (Roth, Schweiger \& Morrison, 1991). 
Global teams can become key means of balancing local responsiveness and global integration (Maloney \& Zellmer-Bruhn, 2006). Diverse team members have different types of localized knowledge about the practices, preferences and values of different regional areas, but they also work together integrating their differences into globally feasible solutions. Global teams allow a broader employment of talent, and they can be an effective way of dealing with local specifics while achieving global coordination.

Yet, while global teams may hold unique features enabling them to effectively balance the needs of global integration and local responsiveness, this is not necessarily easy in practice. Holding a responsibility towards both corporate goals and the local needs of the team members' own respective units can easily lead to conflicts among team members with regard to when to drive global standardization and when to adjust to local preferences. For example, international businesses operate in highly diverse circumstances, and attitudes towards social issues or the role of women, for example, can differ widely among different countries. Teams need to pay attention to both the global integration of ethical standards (Peng \& Lin, 2008; Reimann, 2012), and deal with the rules and belief systems of the local stakeholder environment(s) in which they operate (Hillman \& Wan, 2005; Sherer, Palazzo \& Dirk, 2009).

\section{Global team leader roles and capabilities}

Butler, Zander, Mockaitis and Sutton (2012) argue that successful global leaders perform three different roles: boundary spanner, blender, and bridge maker. This conceptual synthesis of the global leader role builds on deep research roots dating back more than forty years (e.g., Paine, 1971; Organ, 1971) and is one strand of the resurgence of interest among international business researchers in the changing nature of roles (e.g., Hongzhi, Knight, Zhilin, \& Ballantyne, 2014; Reiche, Harzing \& Kraimer, 2009; Tenzer \& Pudelko, 2015). In what follows, we examine how these three cross-cutting capabilities can be leveraged and extended to overcome the globalization challenges discussed above, arguing that it is in the process of finding a balance among these contradictions or dilemmas, that a difference can be made (Holt \& Seki, 2012). While the below discussion focuses on the crucial role of the team leader, it is important to note at this point that team members would also greatly benefit from building these three capabilities, and indeed from a perspective of shared leadership (see Zander, et al., 2015), teams would benefit most if all of their members would be involved in performing these roles.

\section{The boundary spanner role of team leaders}

The boundary spanner role refers to establishing and sharing social ties between the team and its various stakeholders to facilitate the exchange of information, knowledge, people and other resources (Butler et al., 2012; Ernst \& Yip, 2009). Team leaders, who recognize the importance of boundary spanning, will focus their attention not only on the different interests of team members, but also on those of their different stakeholder groups outside team boundaries. As discussed, these stakeholder groups may include firm-internal groups such as the home units of the team members, top management or other teams, or they may be firm-external such as customers, suppliers, institutional actors or interest groups. Central to this capability is the maintaining of legitimacy with all groups without appearing to prioritize one over the other (Wiesenfeld \& Hewlin, 2003). This can 
be achieved, for example, by minimizing differences, increasing alignment and instigating collaborations (Gundling et al., 2011).

Second, boundary spanner capabilities comprise people-oriented behaviors, which allow the team leader to act as a positive broker across cultural, linguistic and organizational barriers (Au \& Fukuda, 2002; Obstfeldt, 2005). The ability to 'navigate and negotiate' such cognitive and physical boundaries (Carlile, 2004) draws from an awareness and ability to take different perspectives and a sensitivity to different values, norms and codes of conduct among the different groups the team deals with (Boland \& Tenkasi, 1995; Nahapiet \& Ghoshal, 1998). Previous research suggests that cognitive complexity and cultural (or linguistic/organizational) knowledge are important skills in this respect (Lücke, Kostova, \& Roth, 2013; Maddux \& Galinsky, 2009; Molinsky, 2007): cultural knowledge of others enables leaders to understand multiple perspectives, and cognitive complexity relates to the leader's ability to "process" and integrate multiple and often conflicting perspectives simultaneously by finding the links between them (Holt \& Seki, 2012). They switch their cognitive and cultural frames with emotional stability and resilience (Block \& Block, 1980; Block \& Kremen, 1996; Hiller \& Hambrick, 2005; Judge \& Bono, 2000).

Finally, the ability to work with and integrate multiple perspectives also enables global team leaders to better respond to the dual challenge of global integration and local responsiveness. In literature, this ability has been dubbed as a global mindset, defined by Levy, Beechler, Taylor \& Boyacigiller (2007, pp. 231-258) as "an openness to and articulation of multiple cultural and strategic realities on both global and local levels, and the cognitive ability to mediate and integrate across this multiplicity". In fact, the concept of global mindset incorporates the different capabilities needed to overcome the globalization challenges nicely into one entity, as it implies both the cultural awareness important for brokering the cultural, linguistic and organizational boundaries discussed above, and the strategic aspect seeking to balance the needs of global and local stakeholders (Levy et al., 2007; Osland et al., 2012) to make decisions and achieve results.

\section{The blender role of team leaders}

Whereas the boundary spanning role focuses on team-external linkages and strategic cooperation, the blender role is primarily concerned with integration on the emotional level within the team. As defined by Butler, et al., (2012), "a blend can be understood as a strong new 'whole', which nevertheless retains the clear individual elements of which that whole is comprised, such as the sound blends found in language (e.g., "str" in strategy)" (p., 242) (see also the related notion of 'cultural fusion'; Janssens \& Brett, 2006).

While blending is undoubtedly important for efficient team processes, increasing cohesion and discouraging team-internal fault lines, it can also be a very effective means of dealing with the new challenges of globalization. This can take place at least on two different levels. First, there is the need to balance between the individual goals and needs of the various team members and the interest of the team as a whole (Brewer, 1991). Achieving and maintaining such optimal distinctiveness is essential to the performance of individual team members regardless of team type, but the emotional regulation of global teams is more complex owing to the inherent language differences (Earley \& Gibson, 2002; Hinds, Neeley \& Cramton, 2014) and so requires active management (Tenzer \& Pudelko, 2015). Second, when global team leaders and members develop positive attachments to one another and a genuine sense of belonging to the team (Earley \& Mosakowski, 2000; Hornsey \& Hogg, 2000) they will experience less anxiety and other negative 
emotions (Tenzer \& Pudelko, 2015) and so be better equipped psychologically to balance the competing priorities of the different stakeholders of the team. Just like global teams as a whole, its individual members will also have to deal with multiple stakeholders (such as the team on the one hand, and the team member's local unit, on the other). Consequently, through blending, leaders and team members can better support each other on the emotional level to integrate, multiple competing priorities at different levels.

\section{The bridge making role of team leaders}

In contrast to the two other roles, the bridge maker role is at once both internally and externally focused. The concept is a relative newcomer to global leadership research (Butler, Zander, Mockaitis \& Sutton, 2012), but corresponds closely with the notion of cognitive social capital (Nahapiet \& Ghoshal, 1998), and has been used previously in other fields such as law, medicine and education (Liljegren \& Zander, 2011). Leaders taking a bridge making role seek first to recognize and understand the differences of his or her team members in terms of their thinking, values, motives and styles (Ang, Van Dyne, Koh, Ng, Templer, Tay \& Chandrasekar, 2007), including listening to and identifying 'hidden' cultural cues (Steers, Sanchez-Runde, \& Nardon, 2010). At the heart of bridging capabilities is the fostering of understanding, interdependence, cohesion and recognition (Abreu and Peloquin, 2004) through discussion and dialogue within the team, which according to DiStephano and Maznevski (2000) is an important driver of high team performance. Different team members, as well as relevant stakeholders, understand the world through their own respective value lenses. The bridge maker leader can rise above sophisticated stereotyping (Osland, Bird, Delano, \& Jacob, 2000) by recognizing this uniqueness and cultural patterning under both face-to-face and virtual work conditions (Davis \& Bryant, 2003) to engender understanding of frames of reference and systems of meaning among team-internal and team-external colleagues (Nahapiet \& Ghoshal, 1998; Mäkelä \& Brewster, 2009),

Second, in addition to facilitating the breakdown of cultural barriers, a bridge maker leader can also encourage the globally dispersed team members together with the team's stakeholders to build a cosmopolitan team identity. Such a cosmopolitan identity transcends the individuals' local boundaries (Lee, 2015) and maintains a level of attachment to both the local groups and the broader environment (Lee, 2014), Accordingly the bridge making role will become increasingly important as global organizations move further towards team-based organizing (Zander, et al., 2015).

Above, we have first discussed the new and interlinking globalization challenges of stakeholder diversity, multiple boundaries, and the simultaneous pressures for local responsiveness and global integration, and then examined how the team leader (and team member) capabilities of boundary spanning, blending, and bridge making might help to overcome them. Next, we will look at a particular case - Robert Heinen and his top management team facing a decision of whether or not to increase the proportion of women at higher management levels at the Japanese operation of a major German bank - to shed light on how the new challenges influence teamwork in practice, and how team leaders can address them through boundary spanning, bridge making and blending, in order to make a difference. 


\section{Case study: DCN Bank in Japan ${ }^{1}$}

Robert Heinen, the general manager of the Japanese branch of German DCN Bank [names are fictitious], and his top management team were faced with the decision of whether or not to increase the proportion of women at higher management levels. Recently, the bank introduced annual performance and potential evaluations in order to assess and review its global talent pool. Much to the surprise of Heinen and his management team, the results showed that women on average scored higher than men at similar position levels in terms of both performance and leadership potential. Up till now though, only one woman had been promoted to senior management and only about 10 per cent of females were considered for the high potential pool. These numbers had prompted an intense debate among members of the top management team, as well as decision makers at headquarters.

During Heinen's four-year tenure as general manager in Japan, the branch had recruited many women, and he generally found them to be well educated, hardworking and competent. Yet, an earlier effort to enhance the career advancement of women had encountered strong opposition from several external stakeholders, including the bank's predominantly Japanese clients and highranking government officials with whom many of DCN Bank's managers had to deal with on a regular basis. Opinions within the branch were also polarized. As leader of the senior management team, Heinen faced a particular cultural challenge. The team was divided between two camps - the expatriate managers who were in favor of fully implementing the bank's global diversity policies; and the Japanese executives who cautioned against making such radical changes instead being responsive to local norms. It was clear to Heinen that before he could address the concerns of the various stakeholders affected by a change in policies, he needed to create unity within the management team and reach at least a minimum level of consensus among the managers and employees of the branch. Heinen was faced with a situation characterized by significant stakeholder diversity, requiring boundary spanning and careful stakeholder communication within and outside the company.

Many of the bank's corporate clients were in overwhelmingly male-dominated industries. These clients were key to the success of the branch. The previous attempt to promote more women to senior management positions had led to critique from several of these clients, who were not accustomed to negotiating with female Japanese managers. Thus, dealing and communicating with these stakeholders required prudence and sensitivity. There was even greater resistance on the part of senior government officials from the various ministries with whom DCN Bank executives had to deal with on a regular basis. Although none of them had complained to Heinen in person, it was an open secret that the old boy network was still alive and thriving in these organizations. In fact, some of DCN Bank's Japanese executives had been hired mostly for their close connections with these (allmale) government officials.

It was this group in particular which represented a traditional, local perspective and cautioned against promoting women to positions that would require close contact with corporate clients and senior government officials. For these reasons, Yoshimi Tamighuchi, the Japanese Head of $H R$, was particularly worried about any radical policy changes. However, he never openly expressed his concerns during formal meetings of the senior management team. Only through the

\footnotetext{
${ }^{1}$ In order to bring the decision making process alive, we have added elements of storytelling into the
} text. An earlier version of the case was published in Stahl et al. (2013). 
grapevine Heinen knew about Tamiguchi's position. By contrast, the predominantly German expatriate managers, who comprised most of the top management team, had a more global view. Especially during meetings they openly supported Heinen's plan to empower talented women. Back at headquarters in Germany, DCN Bank's Global Code for Equal Employment (GCEE) was a firm element of the organization's DNA. The code was implemented several years ago and ensures equal opportunities for all employees regardless of age, gender, race, religion, or sexual orientation. In Japan however, the expatriate managers found themselves in one of DCN Bank's few countries of operation where the GCEE policies regarding gender equality were not yet fully implemented or enacted only partially; based on the assumption that the policies might clash with traditional Japanese norms and values. For the expatriate managers, the results of the potential assessments provided a welcome opportunity to point out that implementing the GCEE policies in Japan was long overdue.

Back at headquarters in Germany, there was also mounting pressure to fully implement the GCEE in Japan. During a recent visit at headquarters, Heinen discussed the issue with both the Vice President of Human Resources and the bank's Global Head of Diversity and Corporate Citizenship. Both clearly emphasized the importance of the GCEE and the full enactment of its principles in all of DCN Bank's countries of operation. In view of talent management considerations, they also made it clear that the bank could not afford losing any valuable talents - be it in Japan or elsewhere. Based on the recent performance and leadership potential evaluations, Heinen realized that the career advancement of women in Japan was not solely a question of ensuring equal opportunities for all employees but a necessary step to tap into an underutilized talent pool on a global scale. In view of the looming talent shortage in Japan, this would give DCN Bank an edge over their competitors.

Among the Japanese employees, Heinen encountered a divide between the elderly, traditionally-oriented generation and younger, more progressive employees. He found that many of the older, male employees resented reporting to a female manager. Some had openly voiced their displeasure with his plan to increase the number of females in senior management positions. They had declared that they would rather quit than work for a female boss. For Japanese standards such resistance was very unusual. It very much reflected the traditional local attitude towards women in business. On the other hand, younger men tended to have fewer reservations about the more contemporary idea of "career women". As for the women themselves, they generally applauded attempts by senior management to improve the career prospects of women in the bank, although some of them admitted that they saw their future roles as mothers and housewives rather than managers - an attitude that baffled Heinen and reinforced his belief that any attempt to enhance the career opportunities of women in the bank would have to be part of a more comprehensive solution that allowed females to balance their careers and family commitments. In addition, such an initiative would have to be communicated carefully to the various stakeholders within and outside the organization. It would also require Heinen and his team to reconcile global and local imperatives, for instance, the need to adhere to the bank's GCEE policies, and the need to be sensitive to local norms and expectations.

After much thought and discussion, and carefully weighting the pros and cons of several alternatives, Heinen and his senior management team launched a three-year program aimed at improving career opportunities for women in the bank. The program, dubbed "Making DCN Bank Japan a Great Place to Work for Women", included training and career coaching for females, changes in career development systems and promotion criteria, various work-life balance options, as well as building awareness for gender issues among male employees. This initiative illustrates that 
Heinen acted as bridge maker, boundary spanner, and blender, addressing the challenges of stakeholder diversity and multiple boundaries, as well as tensions between the need for local responsiveness and global integration.

The longer-term character of the program was crucial in reconciling the expatriates' and the Japanese senior managers' perspectives. By understanding and recognizing the Japanese executives' concerns - especially Yoshimi Tamighuchi's unspoken worries about radical policy changes - Heinen was able to bridge the divide within the senior management team. Despite initial resistance from both the German and the Japanese managers, Heinen clearly signaled to both that the program would carefully address each side's particular concerns. This resulted in better understanding on both fronts, unified the team, and created top-management backing. This support helped Heinen span the boundaries within the organization and the various employee groups, as well as outside the bank, for instance, in the bank's relations to key clients and high-ranking government officials. Heinen and his senior management team went to great lengths to visibly demonstrate at all fronts that gender equality was a top management priority. They made it a point to personally introduce newly hired or promoted female managers to key customers and government officials. Rather than harming long-term business relationships with corporate clients, the initiative was well accepted because of the senior management support behind it and respective communication towards the external stakeholders. Overall, Heinen also acted as blender as he reconciled the need for local responsiveness to the Japanese context with DCN Bank's global integration efforts. Through the program, DCN Bank in Japan significantly increased the proportion of female managers and reduced turnover rates among younger employees. In addition, internal surveys showed that team productivity, job satisfaction and personal motivation among women improved significantly changes that were largely attributed to this program and the sound management of the various stakeholders. By assuming the role of a bridge maker between culturally divided team members, boundary spanner between stakeholders within and outside the bank, and blending global with local realities, Heinen managed to make a difference and overcome the challenges of stakeholder diversity, multiple boundaries, as well as tensions between local responsiveness and global integration.

\section{Discussion}

Our case of Robert Heinen and his team in Japan shows how global teams and their leaders can make a difference by addressing these challenges through boundary spanning, bridge making and blending. First, through boundary spanning, Heinen and his team needed to balance the interests of and find a solution that works with different company-internal stakeholders: On the one hand, local employees, in particular older ones, felt uncomfortable reporting to a female senior manager; on the other hand, the corporate headquarters were pushing for GCEE policies being put in place. What is more, the expectations and interests of company-external stakeholders, most importantly customers many of which held strong traditional values against female managers, needed to be addressed in order to make a difference - after all, any changes could have significant impact on the bottom line.

Second, Heinen's ability to bridge the views of his top management team, who were initially divided, crucially helped him to pull the initiative through. In this role, emphasis was put on understanding and addressing the team members' different goals, interests, and ways of thinking 
through dialogue. Second, since the individual team members will deal with their own multiple stakeholders, recognizing and discussing differences inside the team will be an effective means also towards dealing with external stakeholders. Third, by understanding and finding a way to blend the different values of the individual team members and stakeholders with those of the global organization as a whole, Heinen and his team were able to come to a "new whole" solution that created sufficient legitimacy with both the member of the management team and the teams various stakeholders. The result was a solution that enabled the organization to tap into a broader talent pool, mindfully address an important societal question, and while doing so facilitate the building of competitive advantage for DNC bank in Japan.

The case shows that an awareness of, and an ability to balance the interests of and maintain legitimacy with, all stakeholder groups is vital in order for any team to make a difference. While the strategies Heinen employed were specific to the focal situation, we believe that both the challenges of globalization and the three team leader capabilities are generalizable to many contexts. Hence, we encourage team leaders - and members - to look at their particular issues from the perspectives of stakeholder diversity, multiple boundaries, and global-local tensions, and employ strategies and solutions that are in line with the principles of boundary crossing, bridge making and blending.

We contribute to the literature on team heterogeneity and global leadership in several ways. First, while earlier contributions on global teams have mainly focused on team-internal issues, we go beyond the perspective by considering the embeddedness of the team in its environment. This constitutes very distinct requirements on both the team and the global leader, and suggests that future research should broaden its focus from team-internal processes to looking at teams as organizational actors.

Second, we pay special interest to different internal and external boundaries and how these can be "crossed" through global leader capabilities. While doing this, we recognize an increasing fuzziness in terms of where exactly the boundaries of a team lies, in that global teams are situated within a variety of relationships (firm-external, firm-internal, vertical and horizontal) comprising fluid and complex boundaries. These boundaries do not perfectly overlap and may change over the lifecycle of the team.

Third, we address distinct capabilities of global leaders anchored in three central global leadership roles. We suggest that global leaders can make a difference through leveraging these capabilities in order to actively manage the effects of globalization on the team. Facilitating relationships among team members and to the team external parties is critical not only for team functioning, but also more generally for interconnecting the team with its broader context.

What is more, the expectations on team leaders and leadership will vary across cultures. Leadership is to a large extent culturally contingent, and since team leaders are faced with divergent expectations they must have an understanding for cultural dynamics and the multiplicity of perspectives and interests. As pointed out by Steers, Sanchez-Runde and Nardon (2012), many leadership theories are still built on the assumption that leadership is universal and that leadership models (predominantly based on Western beliefs, values and cultures) are widely spread. In fact, Steers goes as far as to question whether there are certain universal abilities and skills that are common to all managers and put forward the need to "move beyond traditional Western models of leadership and take a more cosmopolitan approach to the subject" (p. 481). Although cultural differences as such are outside our focus, this notion is in line with our argument: In order for global team leaders to make a difference, they need to focus on the accepting and managing interests, perspectives and differences. This frequently means that emphasis has to move from control and 
direction to managing relationships within and external to the team.

TEXT BOX

\section{Ideas for further research}

We illustrate how globalization has affected global teams and team leadership focusing on three key challenges that organizations face: increasing stakeholder diversity, changes in the nature and types of boundaries, and the need for global integration as well as local responsiveness. These new challenges suggest a shift in research focus from team-internal processes to looking at teams as actors in a broader environment. Based on this we suggest future studies to engagement with the following research themes:

- What is the relation between stakeholder diversity and boundary formation between teams, departments and business units in global organizations?

- What is the role of teams in dealing with the global integration vs local responsiveness paradox?

- What is the role of team leadership in aligning stakeholder diversity and global integration vs local responsiveness issues?

\section{Relevance for educators}

Given the three challenges of increasing stakeholder diversity, more and different boundaries, and the need for global integration and local responsiveness, new questions for discussion arise that will broaden the horizon of students:

- What kinds of new stakeholders globalization invites for teams?

- What types of new boundaries do teams need to deal with, both within and beyond the focal firm?

- Why is it so important to consider local responsiveness and global integration simultaneously in teamwork?

\section{Interest to practitioners}

We examined how global leaders can respond to and manage the above challenges of globalization through the three specific roles of boundary spanning, bridging and blending. Our work suggests that as a team leader, you should pay attention to (i) who your various stakeholders are, both in terms of the team as a whole and of its members; (ii) what kinds of boundaries - geographical, functional, cultural/linguistic, organizational - you need to overcome in order to work with them successfully; and (iii) how you - just like Heinen in the DCN Bank case - can use boundary spanning, bridging and blending to overcome the challenges in order to make a difference. 


\section{References}

Abreu, B. and Peloquin, S. (2004), 'The issue is: Embracing diversity in our profession', The American Journal of Occupational Therapy, 58, 353-359.

Alon, I. and Higgins, J. M. (2005), 'Global leadership success through emotional and cultural intelligences', Business Horizons. 48(6), 501-512.

Ang, S., Van Dyne, L., Koh, C.K.S., Ng, K.Y., Templer, K.J., Tay, C. and Chandrasekar, N.A. (2007), 'Cultural intelligence: Its measurement and effects on cultural judgment and decisionmaking, cultural adaptation and task performance', Management and Organization Review, 3, 335-371.

Au, K. and Fukuda, J. (2002), 'Boundary spanning behaviors of expatriates'. Journal of World Business, 37, 285-296.

Ash, S.R. (2008), 'Hispanics and anglos: The role of group composition on satisfaction', Public Personnel Management, 37(1), 15-26.

Bartlett, C.A. and Ghoshal, S. (1989), Managing across borders: The transnational solution. London: Hutchinson Business Books.

Birkinshaw, J. and Hood, N. (1998), 'Multinational subsidiary evolution: Capability and charter change in foreign-owned subsidiary companies', Academy of Management Review, 23(4), 773-795.

Block, J. H. and Block, J. (1980), 'The role of ego-control and ego-resiliency in the organization of behavior', InW. A. Collins (Ed.), Development of cognition, affect and social relations: The Minnesota symposia on child psychology, 13, Hillsdale, NJ: Erlbaum.

Block, J. and Kremen, A. M. (1996), 'IQ and ego-resiliency: Conceptual and empirical connections and separateness', Journal of Personality and Social Psychology, 70, 349-361.

Boland, R. J. and Tenkasi, R. V. (1995), 'Perspective making and perspective taking in communities of knowing', Organization Science, 6, 350-372.

Brannen, M.Y. and Salk, J.E. (2000), 'Partnering across borders: Negotiating organizational culture in a German-Japanese joint venture', Human Relations, 53(4), 451-488.

Brewer, M.B. (1991), 'The social self: On being the same and different at the same time', Personality and Social Psychology Bulletin, 17, 475-482.

Brock, D.M. and Siscovick, I.C. (2007), 'Global integration and local responsiveness in multinational subsidiaries: Some strategy, structure and human resource contingencies', Asia Pacific Journal of Human Resources, 45(3), 353-373.

Butler, C. L., Zander, L., Mockaitis, A. I. and Sutton, C. (2012), 'The global leader as boundary spanner, bridge maker and blender', Industrial and Organizational Psychology: Perspectives on Science and Practice 5(2).

Carlile, P.R. (2004), 'Transferring, translating and transforming: An integrative framework for managing knowledge across boundaries', Organisation Science, 15(5), 555-568.

Chiswich, B.R. and Miller, P.W. (2005), 'Linguistic distance: A qualitative measure of the distance between English and other languages', Journal of Multilingual and Multicultural Development, 26(1), 1-11.

Chomsky, N. (1992), Language and thought. Wakefield: Moyer Bell.

Clément, R. and Gardner, R.C. (2001), 'Second Language Mastery', In W.P. Robinson and P. Giles (Eds.), The New Handbook of Language and Social Psychology. New york: john wiley and sons Itd.

Davis, D.D. and Bryant, J.L. (2003), 'Influence at a distance: leadership in global virtual teams', Advances in Global Leadership, 3, 303-340. 
Distefano, J.J. and Maznevski, M.L. (2000), 'Creating value with diverse teams in global management,' Organizational dynamics, 29(1), 45-63.

Doz, Y.L., Santos, J. and Williamson, P. (2001), From Global to Metanational. Boston: Harvard Business School.

Earley, P. C. and Gibson, C. B. (2002), 'Multinational work teams: A new perspective' New Jersey: Lawrence Erlbaum Associates.

Ealrey, P.C. and Mosakowski, E. (2000), 'Creating Hybrid Team Cultures: An Empirical Test of Transnational Team Functioning', Academy of Management Journal, 43(1), 26-49.

Epton, S.R., Payne, R.L. and Pearson, A.W. (1985), 'Contextual issues in managing cross- disciplinary research', In B.W. Mar, W.T. Newell and B.O. Saxberg (Eds.), Managing high technology: An interdisciplinary perspective. Amsterdam: Elsevier

Ernst, C. and Yip, J. (2009), 'Boundary spanning leadership: Tactics for bridging social boundaries in organization', In T. Pittinsky (Ed.), Crossing the divide: Intergroup leadership in a world of difference. Boston, MA: Harvard Business School Press.

Fassin, Y. (2012), 'Stakeholder management, reciprocity and stakeholder responsibility', Journal of Business Ethics, 109(1), 83-96.

Fiol, M. C. (1989), 'A semiotic analysis of corporate language: Organizational boundaries and joint venturing', Administrative Science Quarterly, 34(2), 277-303.

Freeman, E. (1984), Strategic management: A stakeholder approach. Boston: Pitman.

Friedman, T. L. (2005), The world is flat: A brief history of the twenty-first century. New York: Farrar, Straus and Giroux.

Gibbs, J. (2009), 'Dialectics in a global software team: Negotiating tensions across time, space and culture', Human Relations. 62 (6), 905 - 935.

Gibson, C.B. (2001), 'From knowledge accumulation to accommodation: Cycles of collective cognition in work groups', Journal of Organizational Behavior, 22(2), 121-134.

Govindarajan, V. and Gupta, A. (2001), 'Building an effective global business team', Sloan Management Review, 42(4), 63-71.

Gudykunst, W.B. (2004), Bridging differences: Effective intergroup communication. London: Sage.

Gundling, E., Hogan, T. and Cvitkovich, K. (2011), What is global leadership: 10 key behaviors that define great global leaders. Boston, MA: Nicholas Brealey Publishing.

Hambrick, D. C., Davison, S. C., Snell, S. A. and Snow, C. C. (1998), 'When groups consist of multiple nationalities', Organization Studies, 19, 181-206.

Hannon, J.M. (1995), 'International human resource strategy and its determinants: The case of subsidiaries in Taiwan', Journal of International Business Studies, 26(3), 531-555.

Hargadon, A. and Sutton, R.I. (1997), 'Technology Brokering and Innovation in a

Product Development Firm.' Administrative Science Quarterly, 42, 716-749.

Henderson, J.K. (2005), 'Language diversity in international management teams', International Studies of Management and Organization, 35(1), 66-82.

Hiller, N. and Hambrick, D. C. 2005. 'Conceptualizing executive hubris: The role of (hyper-) core self evaluations in strategic decision-making', Strategic Management Journal, 26, 297-319.

Hillman, A.J. and W.P. Wan (2005), 'The determinants of MNE subsidiaries' political strategies: Evidence of institutional duality', Journal of International Business Studies, 36, 322-340.

Hinds, P.J., Neeley, T.B. and Cramton, C.D. (2014), 'Language as a lightning rod: Power contests, emotion regulation and subgroup dynamics in global teams', Journal of International Business Studies, 45, 536-561. 
Holt, K. and Seki, K. (2012), 'Global leadership: A developmental shift for everyone', Industrial and Organizational Psychology: Perspectives on Science and Practice, 5(2), 196-215.

Hongzhi, G. Knight, J.G., Zhilin, Y. and Ballantyne, D. (2014), 'Toward a gatekeeping perspective of insider-outsider relationship development in China', Journal of World Business, 49(3), 312320.

Hornsey, M. J. and Hogg, M. A. (2000), 'Assimilation and diversity: An integrative model of subgroup relations', Personality and Social Psychology Review, 4, 143-156.

Jackson, S.E., May, K.E. and Whitney, K. (1995), 'Understanding the dynamics of diversity in decisionmaking teams', in R.A. Guzzo and E. Salas (Eds.), Team decision-making effectiveness in organizations, San Francisco: Jossey-Bass, 204-261

Janssens, M. and Brett, J.M. (2006), 'Cutural intelligence in global teams; A fusion model of collaboration', Group and Organization Management, 31, 124-153.

Jarvenpaa, S. L and Leidner, D. E. (1999), 'Communication and trust in global virtual teams', Organization Science, 10, 791-815.

Jehn, K.A., Neale, M. and Northcraft, G. (1999), 'Why differences make a difference: A field study of diversity, conflict and performance in workgroups', Administrative Science Quarterly, 44, 741-763.

Judge, T. A., Bono, J. E., llies, R. and Gerhardt, M. W. 2002. 'Personality and leadership: A qualitative and quantitative review', Journal of Applied Psychology, 87, 765-780.

Kearney, E., Gebert, D. and Voelpel, S.C. (2009), 'When and how diversity benefits teams: The importance of team members' need for cognition', Academy of Management Journal, 52(3), 581-598.

Klitmøller, A. and Lauring, J. (2013), 'When global virtual teams share knowledge: Media richness, cultural distance and language commonality', Journal of World Business, 48(3),

Kogut, B. and Zander, U. (1993) 'Knowledge of the firm and the evolutionary theory of the multinational corporation.' Journal of International Business Studies, 24(4), 625-645.

Lauring, J. and Selmer, J. (2010), 'Multicultural organizations: Common language and group cohesiveness', International Journal of Cross Cultural Management, 10(3), 267-284.

Lee, H-J. (2014), 'Identities in the global world of work', In B. Gehrke and M-T. Claes (Eds.), Global Leadership Practices: A Cross Cultural Management Perspective. London: Palgrave Macmillan, pp. 85-101.

Lee, H-J. (2015), 'Cosmopolitanism', In C. Cooper (Ed.), The Wiley Encyclopedia in Management (3 ${ }^{\text {rd }}$ edition), Vol. 6, International Management. pp.1-2.

Levy, O., Beechler, S., Taylor, S. and Boyacigiller, N. (2007), 'What We Talk About When We Talk About "Global Mindset: Managerial Cognition in Multinational Corporations', Journal of International Business Studies, 38(2), 231-258.

Li, H.Z. (1999), 'Communicating information in conversations: A cross-cultural comparison', International Journal of Intercultural Relations, 23(3), 387-409.

Liljegren, S. and Zander, L. (2011), 'The importance of being a bridge maker: Power and influence in international and multicultural boards of directors', Paper presented at the academy of management annual meeting, San Antonio, USA.

Lücke, G., Kostova, T. and Roth, K. (2013), 'Multiculturalism from a cognitive perspective: Patterns and implications', Journal of International Business Studies, 45(2), 169-190.

Luo, Y. (2001), 'Determinants of local responsiveness: perspectives from foreign subsidiaries in an emerging market', Journal of Management, 27(4), 451-478. 
Maddux, W. W. and Galnsky, A. D. (2012), 'Cultural borders and mental barriers: The relationship between living abroad and creativity', Journal of Personality and Social Psychology, 96, 10471061.

Mäkelä, K. and Brewster, C. (2009), 'Interunit interaction contexts, interpersonal social capital and the differing levels of knowledge sharing.' Human Resource Management, 48(4), 591-613.

Maloney, M.M. and Zellmer-Bruhn, M. (2006), 'Building bridges, windows and cultures: Mediating mechanisms between team heterogeneity and performance in global teams', Management International Review, 46, 697-720.

Maznevski, M.L. and Chudoba, K.M. (2000), 'Bridging Space Over Time: Global Virtual Team Dynamics and Effectiveness', Organization Science, 11(5), 473-492.

McLeod, P.L. and Lobe, S.A. (1992), 'The effects of ethnic diversity on idea generation in small groups', Academy of Management Executive, Best Papers Proceedings, 227-231.

Mendenhall, M.E., Reiche, B.S., Bird, A. and Osland, J.S. (2012), ,Defining the 'global' in global leadership', Journal of World Business, 47(4), 493-50

Molinsky, A. (2007), 'Cross-cultural code-switching: The psychological challenges of

adapting behavior in foreign cultural interactions', Academy of Management Review, 32, 622-640.

Morrison, A. J. (2000), 'Developing a global leadership model', Human Research Management. 39(2/3), 117-131.

Nahapiet, J. and Ghoshal, S. (1998), 'Social capital, intellectual capital and the

organizational advantage', Academy of Management Review, 23, 242-266.

Obstfeld, D. (2005), 'Social networks, the tertius iungens orientation and involvement in innovation', Administrative Science Quarterly, 50, 100-130.

Osland, J. S., Bird, A., Delano, J. and Jacob, M. (2000), Beyond sophisticated stereotyping: Cultural sensemaking in context', The Academy of Management Executive, 14, 65-79,

Organ, D.W. (1971), 'Linking pins between organizations and environment', Business Horizons, 14, 73-80.

Osland,, J., Bird, A. and Oddou, G. (2012), 'The context of expert global

leadership', in William H. Mobley, Ying Wang, Ming Li (ed.) Advances in global leadership, 7, Emerald Group Publishing Limited, 107-124.

Paine, R. (1971), 'A Theory of Patronage and Brokerage', In R. Paine (Ed.), Patrons and brokers in the East Arctic. Toronto: University of Toronto Press.

Palazzo, B. (2002), 'U.S.-American and German Business Ethics: An Intercultural Comparison', Journal of Business Ethics, 41, 195-216.

Peng, Y.-S. and Lin, S.-S. (2008), 'Local responsiveness pressure, subsidiary resources, green management adoption and subsidiary's performance: Evidence from Taiwanese manufactures', Journal of Business Ethics, 79(1-2), 199-212.

Polonsky, M. and Jevons, C. (2009), 'Global branding and strategic CSR: an overview of three types of complexity', International Marketing Review, 26(3), 327-347.

Reiche, B.S., Harzing, A.-W. and Kraimer, M.L. (2009), 'The role of international assignees' social capital in creating inter-unit intellectual capital: A cross-level model', Journal of International Business Studies, 40, 509-526.

Reimann, F. (2012), 'Local stakeholders and local legitimacy: MNEs' social strategies in emerging economies', Journal of International Management, 18(1), 1-27.

Roth, K., Schweiger, D. and Morrison, A.J. (1991), 'Global strategy implementation at the business unit level: Operational capabilities and administrative mechanisms', Journal of International 
Business Studies, 22(3), 369-402.

SanAntonio, P.M. (1987), 'Social mobility and language use in an American company in Japan', Journal of Language and Social Psychology, 6(3-4), 191-200.

Scherer, A., Palazzo, G and Dirk, M. (2009), ,Globalization as a challenge for business responsibilities', Business Ethics Quarterly, 19(3), 327-347.

Snow, C.C., Snell, S. A. Canney Davison, S. and Hambrick, D. C. (1996) 'Use transnational teams to globalize your company', Organizational Dynamics, 24(4), 50-67.

Stahl, G., Mäkelä, K., Zander, L. and Maznevski,M. (2010), 'A Look at the Bright Side of Multi-Cultural Team Diversity.' Scandinavian Journal of Management, 26(4), 439-447.

Stahl, G. K., Maznevski, M., Voigt, A. and Jonsen, K. (2010), 'Unraveling the effects of cultural diversity in teams: A meta-analysis of research on multicultural work groups', Journal of International Business Studies, 41(4), 690-709.

Steers, R. M., Sanchez-Runde, C. J. and Nardon, L. (2010), Management across cultures: Challenges and strategies, Cambridge: Cambridge University Press.

Steers, R.M., Sanchez-Runde, C.J. and Nardon, L. (2012), 'Leadership in a global context: New directions in research and theory development', Journal of World Business, 47(4), 479-482.

Tenzer, H. and Pudelko, M. (2015), 'Leading across language barriers: Managing language-induced emotions in multinational teams', The Leadership Quarterly, 26, 606-625.

Westney, E. (2001), 'Multinational Enterprises and Cross-Border Knowledge Creation.'

In I. Nonaka and T. Nishiguchi (Eds.), Knowledge Emergence: Social, Technical and Evolutionary Dimensions of Knowledge Creation, 147-75. Oxford: Oxford University Press.

Wiesenfeld, B. M. and Hewlin, P. F. (2003),' Splintered identify and organizational change: The predicament of boundary spanning mangers', Research on Managing Groups and Teams, 5, 27-52.

Yagi, N. and Kleinberg, J. (2011), 'Boundary work: An interpretive ethnographic perspective on negotiating and leveraging cross-cultural identity', Journal of International Business Studies, 42, 629-653.

Yu, T., Subramaniam, M. and Cannella, A.A. (2009), 'Rivalry deterrence in international markets: Contingencies governing the mutual forbearance hypothesis', Academy of Management Journal, 52(1), 127-148.

Zellmer-Bruhn, M. and Gibson, C.B. (2006), ,Multinational organizational context: Implications for team learning and performance', Academy of Management Journal, 49(3), 501-518.

Zander, L. and Butler, C.L. (2010), ,Leadership modes: Success strategies for multicultural teams', Scandinavian Journal of Management, 26, 258-267.

Zander, L., Butler, C.L., Mockaitis, A., Herbert, K., Lauring, J., Mäkelä, K., Paunova, M. and Umans, T. (2015), 'Team-based Global Organisations: The future of global organizing', In Drojendijk, R., van Tulder, R. and Verbeke, A. (Eds.), Progress in International Business Research, 10, Bingley: Emerald Group.

Zander, L., Mockaitis, A. and Butler, C.L. (2012), 'Leading global teams', Journal of World Business, 47(4), 592-603.

Zander, L., Zettinig, P. and Mäkelä, K. (2013), 'Leading global virtual teams to

Success.' Organizational Dynamics, 42(3), 228-237. 
